\title{
ENERGY USE IN SHARM EL-SHEIKH RESORT IN EGYPT
}

\author{
M. GEORGEI \& H. BOMBECK \\ Department of Housing Design \& Rural Buildings, \\ Faculty of Agricultural \& Environmental Sciences, \\ University of Rostock, Germany.
}

\begin{abstract}
The world energy demand is projected to grow dramatically over the coming decades and global warming is expected to intensify in the business as usual scenario. Both residential and commercial buildings play a major role in the global energy consumption which has been steadily increasing, reaching the levels of industrial and transportation sectors. This has raised concerns over supply and depletion of energy resources and its resulting environmental impacts considering that oil is the world's vital source of energy and will remain so for many years to come. Although there are no collective data available on the global energy consumption in the hotel sector, yet several studies have indicated that hotel units are among the largest energy consumers in the building sector. A literature review indentifies the lack of published data on energy use in hotels in Egypt. The main aim of this work is to evaluate the energy consumption of resorts as a first step toward establishing a database for resorts key performance indicators in Egypt. This paper, accordingly, investigates the energy performance of five star resorts in the city of Sharm El-Sheikh located on the Red Sea coast in Egypt. This investigation is carried out as part of a study aimed at evaluating the prospects of solar resorts and environmental sustainability in Egypt. The results of the energy audit indicate a common trend of consumption at resorts in Sharm El-Sheikh which is comparable with consumption values of some other hotels in different parts of the world. However, there is potential for introducing energy efficiency measures in resorts and achieving lower consumption levels. Keywords: CO2 emission, electricity use, energy consumption, energy efficiency, environment, solar energy, sustainable tourism.
\end{abstract}

\section{INTRODUCTION}

Over the past six decades, tourism has experienced a continuous expansion and diversification in order to become one of the largest and fastest growing economic sectors in the world. In spite of occasional shocks, international tourist arrivals have shown virtually uninterrupted growth particularly fast in the world's emerging regions. The share in international tourist arrivals received by emerging and developing countries has steadily risen, from 32\% in 1990 to $47 \%$ in 2009 [1]. The Middle East has been one of those fastest growing regions in the past few years. The World Tourism Organization (UNWTO) [1] expects a growth rate of $7.1 \%$ in the number of tourism visiting the Middle East.

In Egypt, tourism has grown rapidly and almost continuously over the past 20 years. It is recognized to be one of the largest contributors to Egypt's economic growth where most of the sector's new tourism jobs and businesses are being created. Many new tourism developments are taking place in Egypt inflicting a larger burden on the existing power plants and leading to increased $\mathrm{CO}_{2}$ emissions. This paper is intended to be used as a guidance document for project developers, investors, lenders, government authorities in the tourism sector who are interested and involved in promoting renewable energy in Egypt and environmental sustainability. The outcome of this study establishes the beginning of a database which would provide information on main issues relative to the assessment and development of energy production systems of a five star resort in Sharm El-Sheikh and neighboring areas.

Hotels and resorts classified as five stars are chosen as a focus point in this investigation since they generally use more energy per visitor compared with other types of touristic accommodation, through their energy intense facilities, such as bars, restaurants, air-conditioning, pools and more spacious rooms. Table 1 provides a global overview of the energy use in different types of accommodation establishments. 
Table 1: Global energy use accommodation [2].

\begin{tabular}{lccccc}
\hline $\begin{array}{l}\text { Accommodation } \\
\text { establishment }\end{array}$ & $\begin{array}{c}\text { Energy use per } \\
\text { bed night (MJ) }\end{array}$ & $\begin{array}{c}\text { Beds } \\
\text { (millions) }\end{array}$ & $\begin{array}{c}\text { Bed nights } \\
\text { (millions) }^{\mathrm{a}}\end{array}$ & $\begin{array}{c}\text { Energy } \\
\text { use (PJ) }\end{array}$ & $\begin{array}{c}\mathrm{CO}_{2} \text { emissions } \\
(\mathrm{mT})^{\mathrm{b}}\end{array}$ \\
\hline Hotels & 130 & 15.98 & 2700.6 & 351.1 & 55.7 \\
Campsites & 50 & 9.05 & 995.5 & 49.8 & 7.9 \\
Pensions & 25 & 4.06 & 686.1 & 17.2 & 2.7 \\
Self-catering & 120 & 3.62 & 611.1 & 73.4 & 11.6 \\
Holiday villages & 90 & 0.75 & 126.8 & 11.4 & 1.8 \\
Vacation homes & 100 & 0.68 & 49.6 & 5.0 & 0.8 \\
Total & - & 34.14 & 5170.4 & 507.9 & 80.5 \\
\hline
\end{tabular}

a A global occupancy rate of $46.4 \%$ was assumed here for the categories hotels, pensions, self-catering, and holiday villages; for campsites, a lower occupancy rate of $30 \%$ was assumed, taking into consideration strong seasonal variations, and for vacation homes, an occupancy rate of $20 \%$ was used. ${ }^{\mathrm{b}}$ Based on an emission factor of $43.2 \mathrm{~g} \mathrm{C} / \mathrm{MJ}$ (Schafer and Victor, 1999 for the 1990 world electricity generation mix).

A few studies address the issue of environmental performance in the tourism industry, especially outside Europe, in spite of the environmental impacts resulting from hotel operation [3, 4]. Field studies show that most hotels use energy inefficiently due to overestimating the energy requirements during the design phase, neglecting the consumption criteria while selecting equipment during the procurement phase and lack of energy management during the operational phase.

This paper, accordingly, investigates the current situation of the hotel industry and the energy performance in the resorts of Sharm El-Sheikh. The first part of this paper gives an overview on the energy sector and the growing tourism industry in Egypt. The location and climate conditions for the chosen case study, Sharm El-Sheikh, are presented to establish a common understanding among the readers. The second part of this paper outlines the objective of the investigation carried out while the third part presents the results obtained from a walk through audit conducted among the resorts in Sharm El-Sheikh. The results are presented per guest-night (GN) representing a preliminary benchmark for hotels located on the Red Sea coast in Egypt that can be used in development and evaluation of design alternatives for resorts in similar environmental locations.

\section{THE TOURISM INDUSTRY IN EGYPT}

Egypt has always been a country of tourism, famous for its antiquities dating back to the various eras and civilizations, however, over the last 20 years, recreational tourism domain has grown rapidly at several unique destinations such as Sharm El-Sheikh, Hurghada, Safaga, Taba and others places located on both the Red Sea and the Mediterranean Sea. According to the Central Bank of Egypt, tourism resembles $36.4 \%$ of the total exported services and accounts for $23 \%$ of the country's foreign currency income. Egypt has accordingly embarked onto implementing a program for promoting the Egyptian tourism during the period 2006-2011 with the main objective of increasing its share in the world tourism market to $1.2 \%$ by 2017 which is equivalent to 16 million tourists. This leap from a tourists number of 6 million measured in 2003 requires an increase in the accommodation capacity. Figure 1 demonstrates the expected growth in guest room numbers in terms of the growth prediction and the government's plan to attract more tourists. In 2017, the guest rooms' number should increase by at least 71,000 newly constructed rooms which is equivalent to around 220 new hotels and resorts [5]. 


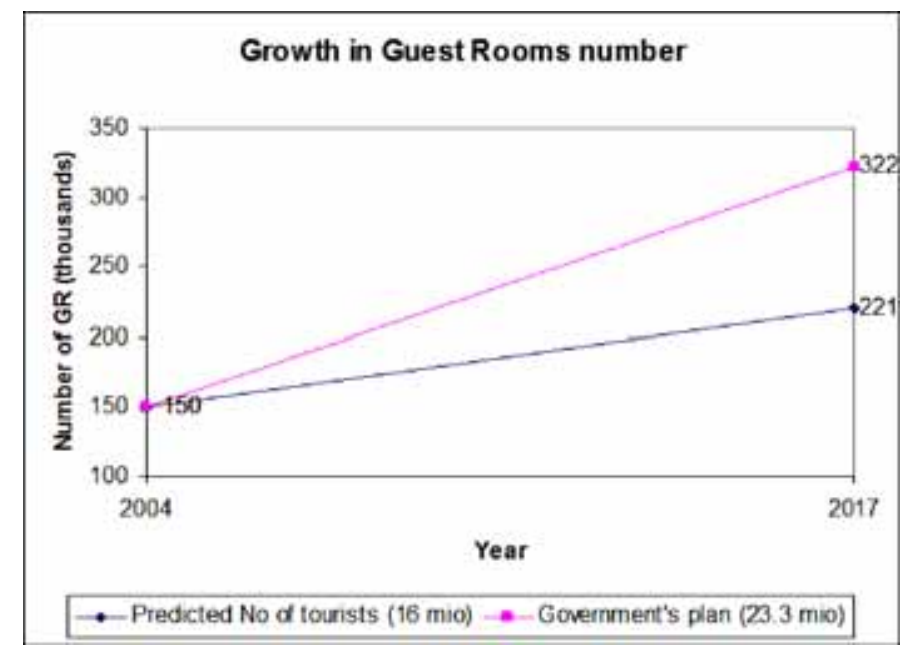

Figure 1: Expected growth in guest room numbers [5].

\subsection{Red Sea development in Egypt}

Being one of Egypt's premier tourism destinations, the Red Sea receives over 1.2 million tourists annually [6]. Egypt is currently developing the Red Sea coast region, which was until recently considered a remote non-inhabited area of the country and had very few economic activities. In the year 2000, the existing number of rooms was 10,549 representing $22.2 \%$ of the total hotel accommodation capacity in Egypt. The target for the year 2012 is to achieve 140,000 rooms primarily by constructing new resorts and secondly by expanding the existing ones [7]. Accordingly, some 90\% of Egypt's tourism investment was concentrated in the coastal resorts of southern Sinai, with a product portfolio centered on dive tourism and beach holidays around the Red Sea and Gulf of Aqaba [8].

At this point, it is important to emphasize that those ambitious development plans to receive 16 million tourists by 2017 should take into consideration sustainability and renewable energy concepts. The government and developers have significant roles to play in adopting and implementing environmentally sound policies and practices to avoid the degradation of the natural heritage of Egypt for the sake of the current as well as future generations [7].

\subsection{Energy in Egypt}

Egypt's energy mix is dominated by oil and gas, which is expected to continue so until 2030 accounting for $95 \%$ of its primary energy demand. Energy demand in Egypt is projected to grow at an average annual growth rate of 2.6\% [9]. Meanwhile, Egypt has an extensive system of social subsidies amounting to 26.3 billion Egyptian pounds (EGP) in 2004 (roughly 2\% of GDP). These subsidies cover a variety of sectors, including the energy sector (petroleum products and electricity) which account for the bulk of the subsidies [9]. As those subsidies present a burden on the country's budget while they also encourage growth in energy demand and consumption, the Egyptian government plans to reduce subsidies with the aim of complete elimination over the next 5 years [8]. Consequently, as these conventional fuels become increasingly expensive, the need to reduce energy consumption and switch to renewable energy becomes even more pressing. 
Meanwhile, an increase in Egypt's $\mathrm{CO}_{2}$ emissions is projected at an average annual rate of $2.6 \%$, from $122 \mathrm{Mt}$ in 2003 to $151 \mathrm{Mt}$ in 2010 and $242 \mathrm{Mt}$ in 2030 [9]. The main emitters of green house gases (GHG) in Egypt are fuel combustion accounting to $22 \%$ in the energy sector, $21 \%$ in the industry sector and $18 \%$ in the transport sector [11]. On the basis of these rough assumptions for all sectors, the total GHG emissions of Egypt are expected to rise to 345\% above 1990 levels until 2017. The energy sector is expected to remain by far the major source for GHG emissions in the future and to increase its share with the highest growth rate [12]. This presents another compelling reason to monitor and reduce energy consumption in hotels and resorts.

\section{ENERGY AUDIT OF SHARM EL-SHEIKH RESORT}

\subsection{Case study of Sharm El-Sheikh resort}

Lying at the southern flank of the Peninsula where the two gulfs of Aqaba and Suez meet with the Red Sea, Sharm El-Sheikh is the biggest and most important city of Sinai and is considered as the most famous seaside resort in Sinai. Sharm El-Sheikh is situated at latitude $27^{\circ} 58^{\prime} 37^{\prime \prime} \mathrm{N}$ and longitude $34^{\circ} 23^{\prime} 40^{\prime \prime} \mathrm{E}$, where it enjoys a very arid desert climate with two main seasons, both of which are dry seasons. Figure 2 shows the average air and water temperatures in Sharm El-Sheikh throughout the year. The winter months are from November to March, during which the day temperature is still warm but the nighttime temperature can drop to about $12^{\circ} \mathrm{C}$ and lower inland in the desert. The annual rainfall is zero; during the winter months it can rain for a few seconds and every few years a storm can come through where it absolutely chucks it down with floods and power cuts. The summer weather is very hot and dry with low humidity making the high temperatures a lot more bearable. The temperature during the day can be in the 40s and decrease during the nighttime to mid-30s.

Among the various uses of electricity, cooling contributes substantially to the electricity demand in summer when temperatures and humidity are high. Air conditioning is widespread not only along the Red Sea coast but all over Egypt. Low energy prices which are strongly subsidized by the government provide no incentive to consumers to apply energy efficient measures or to use renewable energy. Efficiency standards are absent not only in Egypt but in the Middle East region as well.

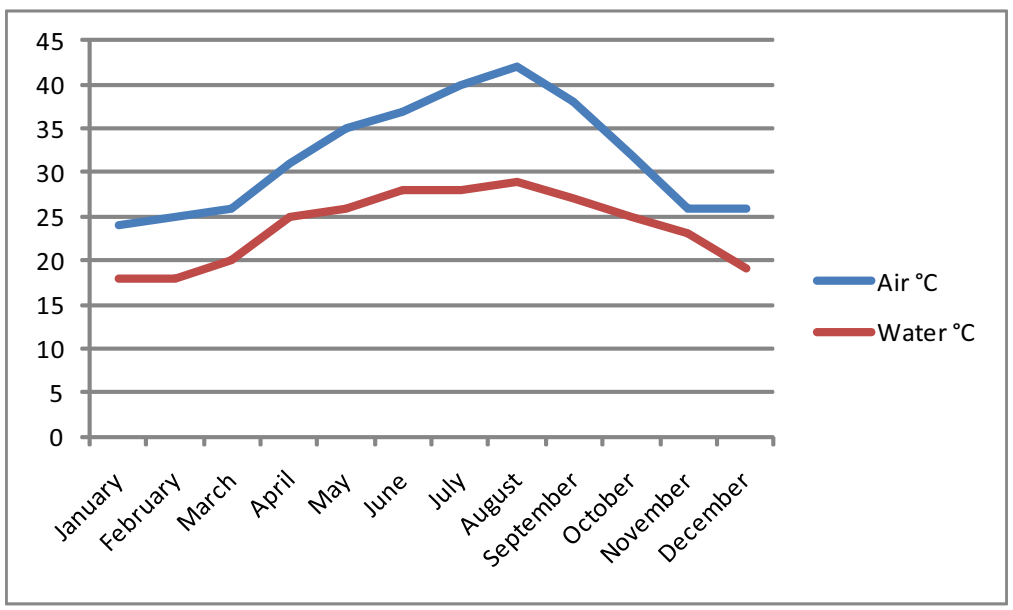

Figure 2: Average air and water temperatures in Sharm El-Sheikh [13]. 


\subsection{Objective of the energy audit}

Responding to the increasing demand for leisure tourism on the Red Sea, the Tourism Development Authority (TDA), with funding from the US Agency for International Development (USAID), introduced the 'Best practices for Tourism Centre Development along the Red Sea coast' in 1998. Five years later, TDA, through the Red Sea Sustainable Tourism Initiative (RSSTI) introduced the series of best practices covering energy management and water and sanitation. The Best Practice for Energy Management covers considerations for improving the energy efficiency of buildings and focuses on the efficiencies of air conditioning, pumps and lighting but does not expose any information with regards to either consumption rates or installation and operation costs [14]. Although TDA mentions the concept of benchmarking in its best practice guide, yet there are no benchmark figures available. Furthermore, there are hardly any academic researches that have been conducted on resorts in Egypt and their key performance indicators which results in the lack of information about energy consumption and its utilization.

Therefore, the objective of this energy audit carried out in Sharm El-Sheikh was to gather information on design practices and the energy performance of five stars resorts with the aim of establishing a database and a benchmark for resorts key performance indicators. The audit also identified the existence of a common trend in energy and water consumptions in Sharm El-Sheikh resorts.

\subsection{Audit structure}

The first step in the energy audit was to carry out a survey on the type and capacities of the resorts located in Sharm El-Sheikh. According to the latest data provided by the Information Centre of Sharm El-Sheikh Governorate, there are a total number of 126 resorts and hotels in Sharm ElSheikh, of which $29 \%$ are five stars hotels, $30 \%$ are four stars and the remaining are of lower classes. This means that more than 59\% of the resorts in Sharm El-Sheikh provide high standard services and facilities which consequently results in higher energy demand. Figure 3 indicates the number of

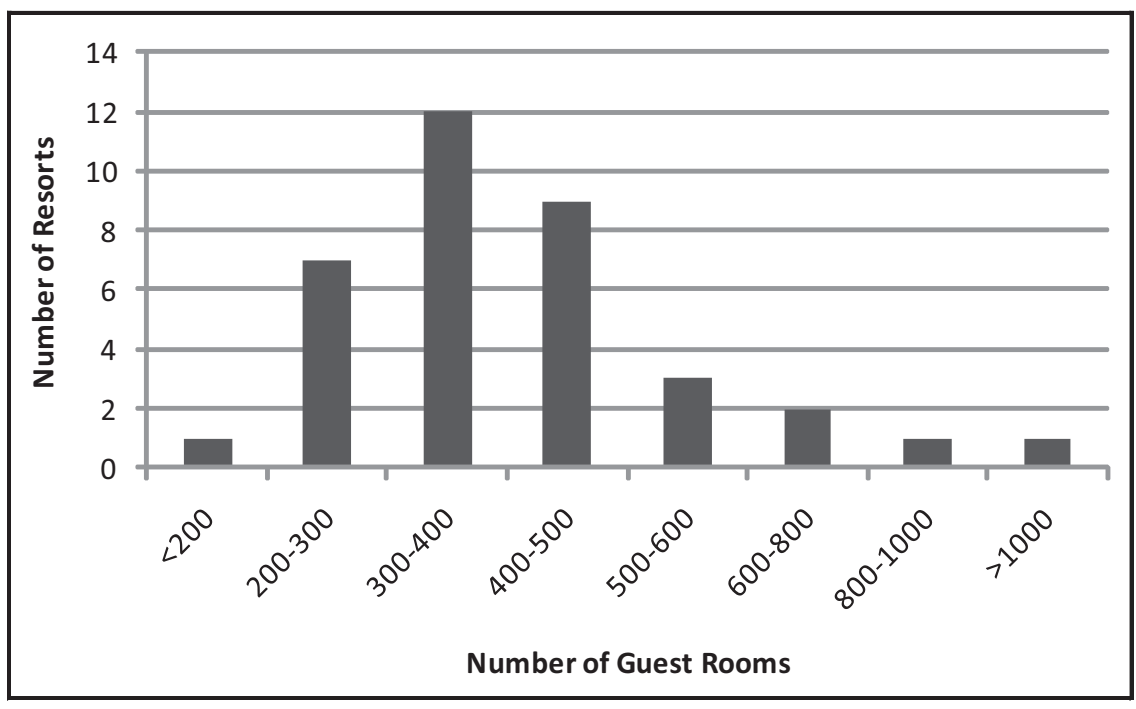

Figure 3: Resorts accommodation capacities in Sharm El-Sheikh. 
resorts versus their accommodation capacities. It is noticed that the majority of resorts have a capacity of 200-500 guest rooms which according to resort developers resembles the most economic scenario considering the existing room rates in Sharm El-Sheikh.

In order to establish a common basis for comparison, the second step in the audit identifies the resorts sharing common features. For example, a five stars resort will provide the same level of services and amenities, and would have similar average room area, devices and equipment; an experienced hotel management will have more or less similar energy management awareness that might be significantly different from local management companies with less experience. Accordingly, the audited resorts were selected to meet the following criteria:

1. Resorts classified as five stars;

2. Operated by experienced and international hotel management;

3. With a minimum number of 200 rooms;

4. Providing fresh water through onsite desalination station;

5. Having an onsite wastewater treatment system;

6. Reusing treated wastewater in landscape irrigation.

The last three criteria are of high importance in calculating and comparing the energy consumption due to their direct role in energy consumption. The more water is consumed, the larger the operation of the water desalination and wastewater treatment plants would be.

The third step in the audit scheme was to formulate the audit questionnaire aimed at collecting the relative data. The questionnaire was sent to a list of five star resorts which met no response at all. This was followed by onsite interviews carried out in 2007 and 2008. Due to time and financial constraints in addition to general reluctance and low levels of response, the authors were not able to interview all 36 five stars resorts in Sharm El-Sheikh. Out of the 36 resorts classified as five stars, only 14 resorts, fulfilling the above set criteria, agreed to participate in the energy audit forming a response rate of $39 \%$. Only 7 out of those 14 resorts provided consistent and complete information that could be further analyzed and used, representing 19\% of the five stars resorts in Sharm ElSheikh. Respecting their data protection policy, it was agreed to present the results of the survey anonymously without mentioning the name of the resorts.

\section{RESULTS OF THE RESORTS SURVEY AND ENERGY AUDIT}

The Egyptian Ministry of Tourism (MoT) has defined a set of standards for the different classes of resorts. These standards are respected by architects during the development of a new resort project. Most of the resorts are designed to have a maximum view of the sea and/or the swimming pools in order to add this advantage to the rooms attributes. The result is high exposure of the façades to sun radiations with nearly no attention paid to the type of glazing, shading and insulation. It is common that the resort will consist of a combination of the following building types:

- Multi-storey building with maximum four stories high;

- Cluster of blocks where each block consists of a ground and first floor and would contain up to six guest rooms;

- Individual chalets or bungalows.

The architect is, usually, influenced by the owner to maximize the number of guest rooms in order to increase the return of investment. The types of materials chosen for construction are mainly based on reinforced concrete for the skeleton and single walls and glazing for the envelope. It is very seldom that thermal insulation is used. 
Various types of energy are required to operate the engineering services installations at the resorts which mainly include heating, ventilation and air conditioning (HVAC), lighting, vertical transportation and hot water supply. Additional heat and power are also consumed in the resort's kitchen and laundry facilities. In Sharm El-Sheikh, three types of energy: electricity, gas and diesel fuel are normally used; diesel fuel is mainly used to operate steam or hot water boilers while liquefied petroleum gas (LPG) may be used in some kitchen equipment. Sharm El-Sheikh is one of the few towns on the Red Sea coast which have access to the public electricity grid; most of the resorts are connected to the grid and only a very few depend on diesel generators for their power supply. Fresh water is supplied through own seawater desalination plants due to the lack of a municipal water distribution system in Sharm El-Sheikh. Nearly all desalination stations constructed on the Red Sea resorts are of reverse osmosis (RO) type known for their high power consumption. Similarly, there is no municipal sewage network in Sharm El-Sheikh and, hence, resorts are required to treat their wastewater and to either reuse or dispose of the treated effluent in an environmentally friendly way.

\subsection{Characteristics of the audited resorts}

An overview of the seven resorts subject to the complete audit is presented in Table 2 . The audited resorts have a room capacity lying between 200 and 550 guest rooms except for Resort 5 which has a capacity of 835 guest rooms. The gross area is defined as the total surface area of the resort divided by the total number of guest rooms. It can be noted that except for Resorts 5 and 6, the resorts have a gross area ranging from 161 to $286 \mathrm{~m}^{2}$ per guest room. This is attributed to the large landscape areas in Resorts 5 and 6 compared with the remaining resorts. Additionally, the seven resorts shared the following features:

- Swimming pools: all resorts have more than one swimming pool with at least one heated during the winter time.

- HVAC: the public areas of all resorts are cooled using central air conditioning with chiller systems. Two out of seven resorts use central chiller system for the cooling of the guest rooms while one resort uses split units for cooling their guest rooms. The remaining four resorts use a mix of central and split systems to air condition their guest rooms. All HVAC systems are power operated.

- Electricity: in all seven resorts, electricity is provided through the grid.

- Domestic hot water (DHW): only one resort use solar thermal energy for supplying DHW while the other six resorts use fuel-operated boilers.

- Kitchen: four resorts use a mix of LPG and electricity to operate the kitchen equipment while the other three resorts depend $100 \%$ on electricity.

Table 2: Overview of the seven audited resorts.

\begin{tabular}{lccccc}
\hline Resort reference & Classification & $\begin{array}{c}\text { Guest room } \\
\text { number })\end{array}$ & Opening date & $\begin{array}{c}\text { Total surface } \\
\text { area }\left(\mathrm{m}^{2}\right)\end{array}$ & $\begin{array}{c}\text { Gross area } \\
\left(\mathrm{m}^{2} / \text { guest room }\right)\end{array}$ \\
\hline Resort 1 & 5 stars & 520 & 1996 & 120,000 & 231 \\
Resort 2 & 5 stars & 314 & 1999 & 68,000 & 217 \\
Resort 3 & 5 stars & 401 & 2000 & 70,000 & 175 \\
Resort 4 & 5 stars & 210 & 1998 & 60,000 & 286 \\
Resort 5 & 5 stars & 835 & 1999 & $357,000,00$ & 428 \\
Resort 6 & 5 stars & 344 & 2004 & 150,000 & 417 \\
Resort 7 & 5 stars & 552 & 2001 & 80,000 & 161 \\
\hline
\end{tabular}


- Laundry: the laundry facilities use steam or hot water supplied by boilers except for Resort 4 which stated using solar thermal energy.

- Guest rooms: the peak power demand per guest room varies between 2 and $6 \mathrm{~kW}$.

- Building energy efficiency measures: none of the resorts use thermal insulation in their external walls while only one resort use double glazing in their window façades.

\subsection{The energy performance of the audited resorts}

The energy performance of the resorts is expressed in this study as $\mathrm{kWh}$, liter and $\mathrm{kg}$ per GN for electricity, fuel and LPG, respectively. The energy intensity unit is chosen GN rather than guest room or sq. meter in order to reflect the occupancy level of the resort which has a direct impact on consumption. The following operational data were accordingly used to calculate the occupancy and consumptions per GN:

- Monthly consumptions for electricity, fuel, LPG and water.

- Annual total number of guests.

- Annual total number of occupied guest rooms.

- Unit price of related consumables such as power, fuel and LPG.

The audit identified that only two out of the seven resorts recorded their consumptions from their first year of operation while the remaining five resorts started recording their consumptions only at a later stage. Figure 4 shows the history of the data recorded versus the opening date.

\subsubsection{Resorts occupancy}

The occupancy of any resort is determined by the guest-to-room ratio and the room occupancy. The guest-to-room ratio shows the average number of guests occupying one sold room. It is defined as the ratio of GNs or bed-nights to the room-nights occupied. Figure 5 depicts the guest-to-room ratio

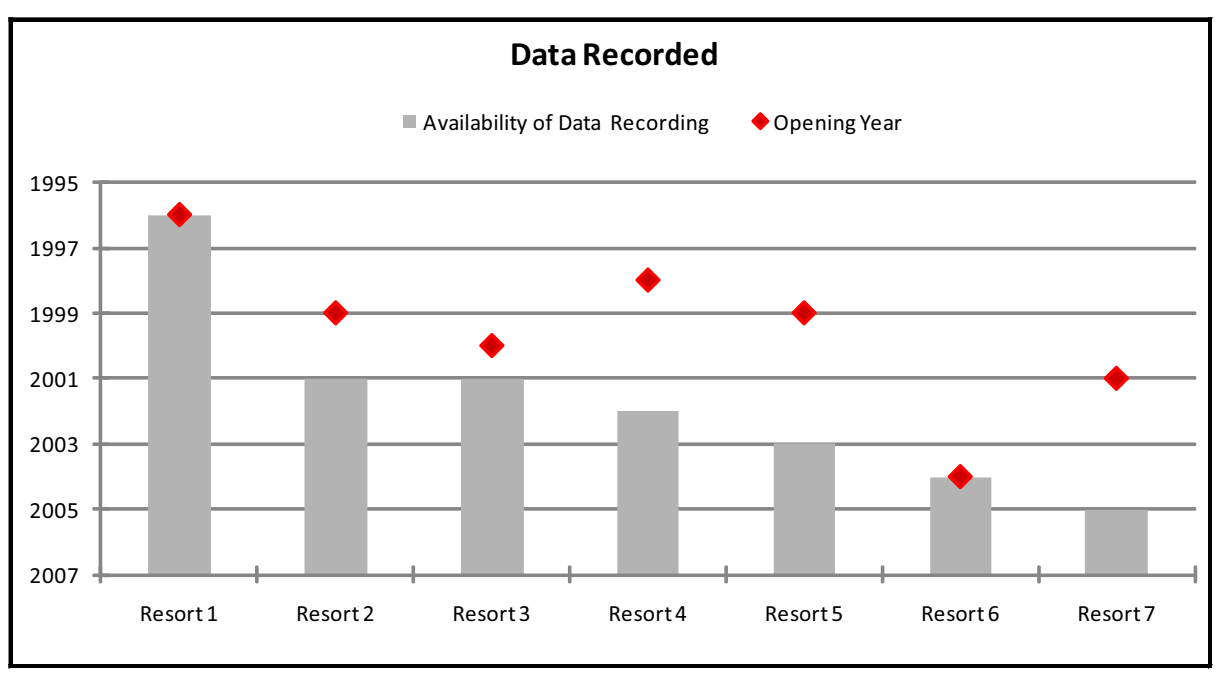

Figure 4: Data recorded vs. year of opening for the interview resorts. 


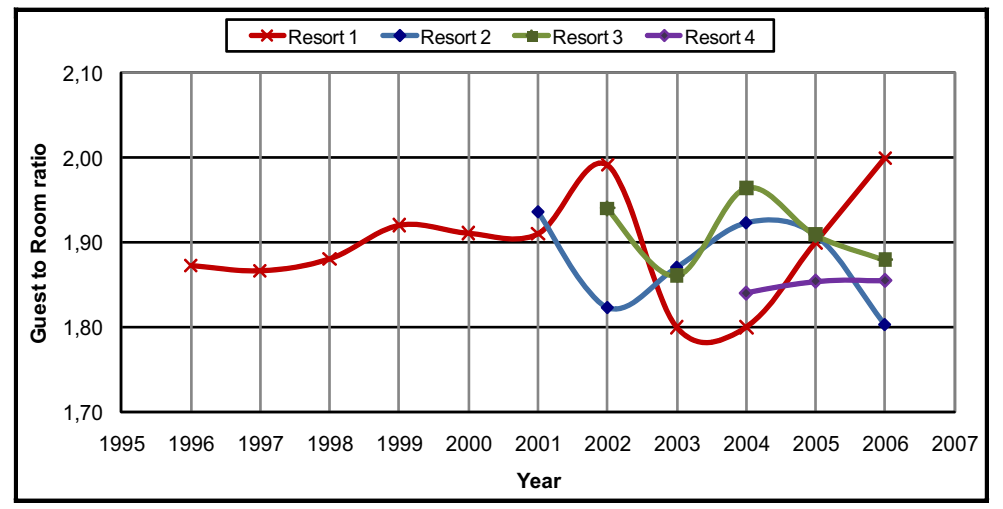

Figure 5: Average guest-to-room ratio at Sharm El-Sheikh resorts.

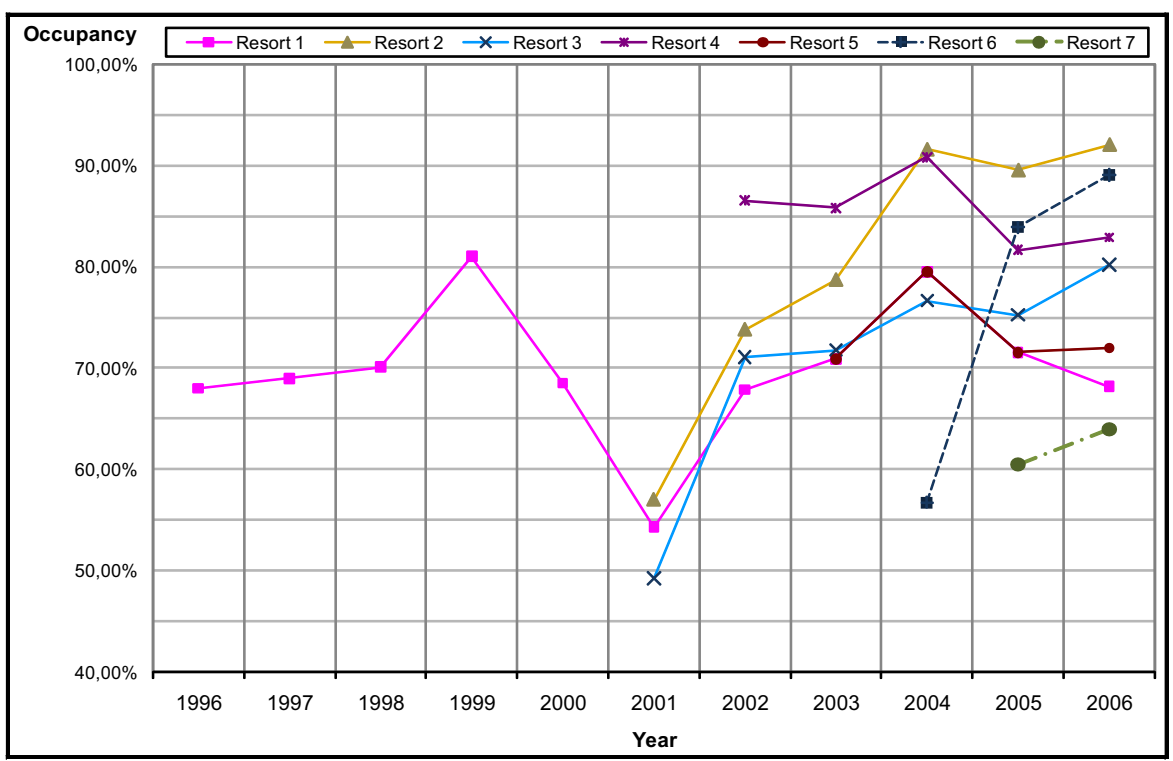

Figure 6: Room occupancy rate at Sharm El-Sheikh resorts.

of the audited resorts between the years 1995 and 2006 where it varies between 1.80 and 2.0 yielding an average value of 1.89 .

Meanwhile, the room occupancy is defined as the number of room-nights occupied divided by the number of room-nights available, multiplied by $100 \%$. Figure 6 shows an average yearly room occupancy ranging between $70 \%$ and $90 \%$. In the period from 2002 to 2006 , five out of the seven resorts showed same trend in the occupancy behavior.

\subsubsection{Resorts electricity consumption}

Electricity is used to power most of the resorts services such as lighting, TV, elevators, part of the cooking devices, electrical appliances, laundry equipment, HVAC system, desalination plant and wastewater treatment plant. The electricity consumption of each resort was calculated using their 


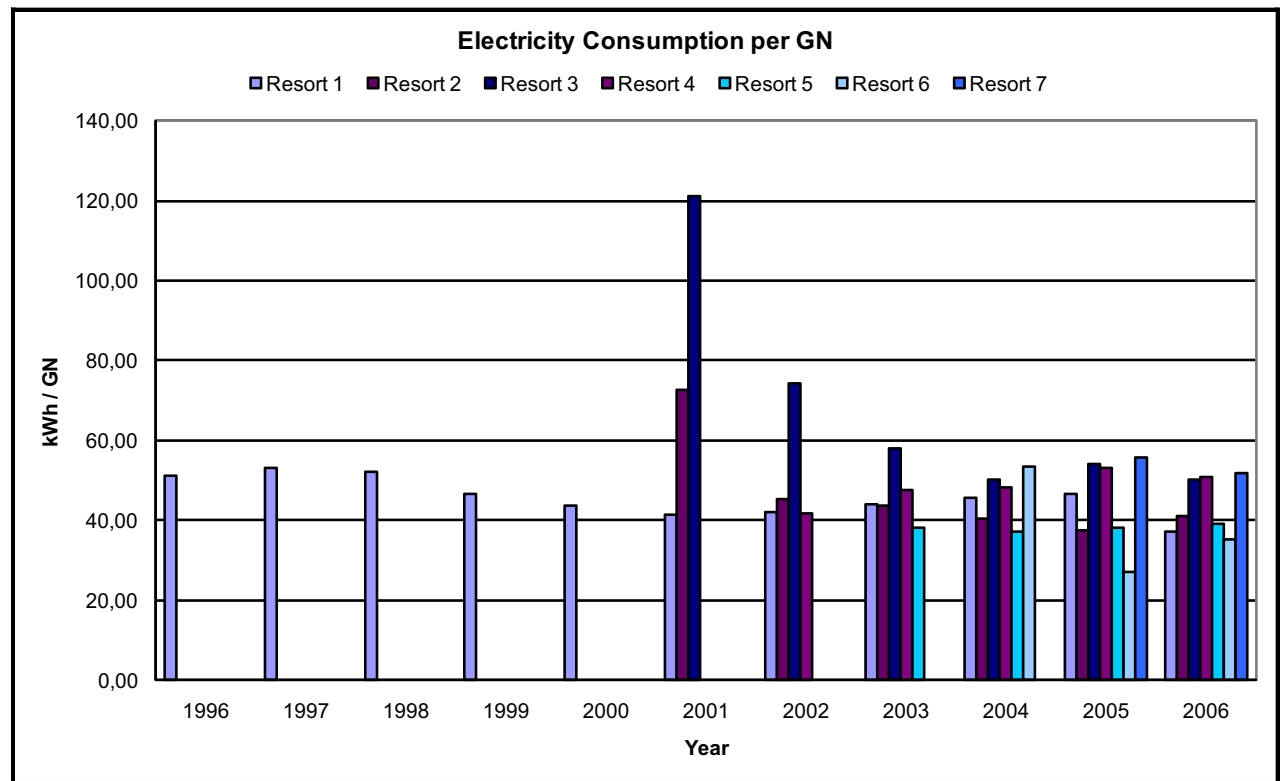

Figure 7: Average electricity consumption per GN at Sharm El-Sheikh resorts.

Table 3: Average energy consumption for hotels worldwide $[3,15]$.

\begin{tabular}{lc}
\hline Country (data for the year) & Average energy use (kWh/GN) \\
\hline Europe (1990s) & 55.5 \\
New Zealand (1999) & 43.1 \\
Zanzibar (2000) & 71.1 \\
Cyprus (2001) & 24.2 \\
Majorca (2001) & 14.2 \\
Italia - Northern Adriatic & 13.5 \\
Croatia - Istria and Kvaerner & 7.5 \\
Slovenia - Istria and Julian Alps & 8.4 \\
\hline
\end{tabular}

monthly electricity billing information. There was no information available on the consumption distribution showing the consumption of each department or function which can be used in identifying high consumers. There were also neither daily consumption profiles nor hourly data available which could show the peak periods during the day. This kind of detailed information is important for design of energy management systems where the energy loads can be optimized by redistributing the operation hours of some equipment. The results of the data analysis for electricity consumption are presented in Figure 7, where it is observed that the average electricity consumption lies between 38 and $58 \mathrm{kWh}$ per GN with the exception of Resort 3 in 2001 and 2002 and Resort 2 in 2001.

The consumption figures of Sharm El-Sheikh are compared with the figures of the study carried out by Bohdanowicz and Martinac [15] for hotels in different parts of the world as indicated in Table 3. It is noted that electricity consumption in Sharm El-Sheikh is comparable with that of Europe and 


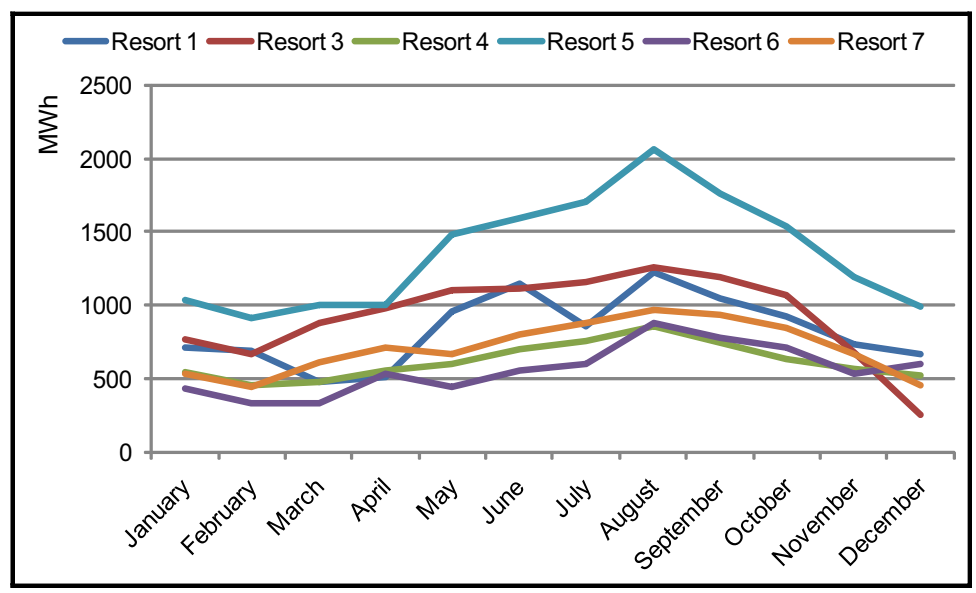

Figure 8: Monthly electricity consumption in 2006 at Sharm El-Sheikh resorts.

New Zealand while higher than that of Cyprus and Majorca. Other benchmark values could not be used for comparison as they are expressed in $\mathrm{kWh} / \mathrm{m}^{2}$ and do not reflect the occupancy rate of the establishment.

The monthly consumption graph in Figure 8 shows the consumption profile in the year 2006 chosen as a representative year. It is observed that during the summer time from June to October there is an increase in the power consumption resulting from the increased cooling demands.

\subsubsection{Resorts fuel consumption}

Diesel fuel is used in resorts mainly for steam/hot water boilers and power generators. All resorts have an emergency generator for cases of electricity cut-off and as stipulated by the MoT. It was stated by all the audited resorts that the fuel consumption of the generators is negligible as they are only operated for very few hours per year and they do not experience long periods of power cut-off from the grid.

Resort 4 is the only resort that do not use boilers and depend on solar thermal collectors for the provision of hot water for domestic and laundry usages and, hence, has almost no fuel consumption at all. Monthly fuel billing information was used to calculate the fuel consumption per GN. Figure 9 presents the computed valued of the fuel consumption for each resort. The average fuel consumption lies between 1.5 and 3 liters per GN. The total monthly fuel consumption (Figure 10) shows a drop in the consumption rates during the spring and summer periods from May to October which is attributed to the lower heating demands for DHW and swimming pools during summer time.

\subsubsection{Resorts LPG consumption}

LPG is used to operate some cooking equipment. Only four out of the seven resorts use a mix of gas and electricity for their kitchen equipment. The gas consumption differs greatly from one resort to the other depending on the proportion of gas to electric equipment. Some resorts depend on $95 \%$ gas supply, others on $75 \%$ or less. This variation is reflected in the consumption rates which significantly differ from one resort to the other making it not possible to identify the LPG use behavior in Sharm El-Sheikh. 


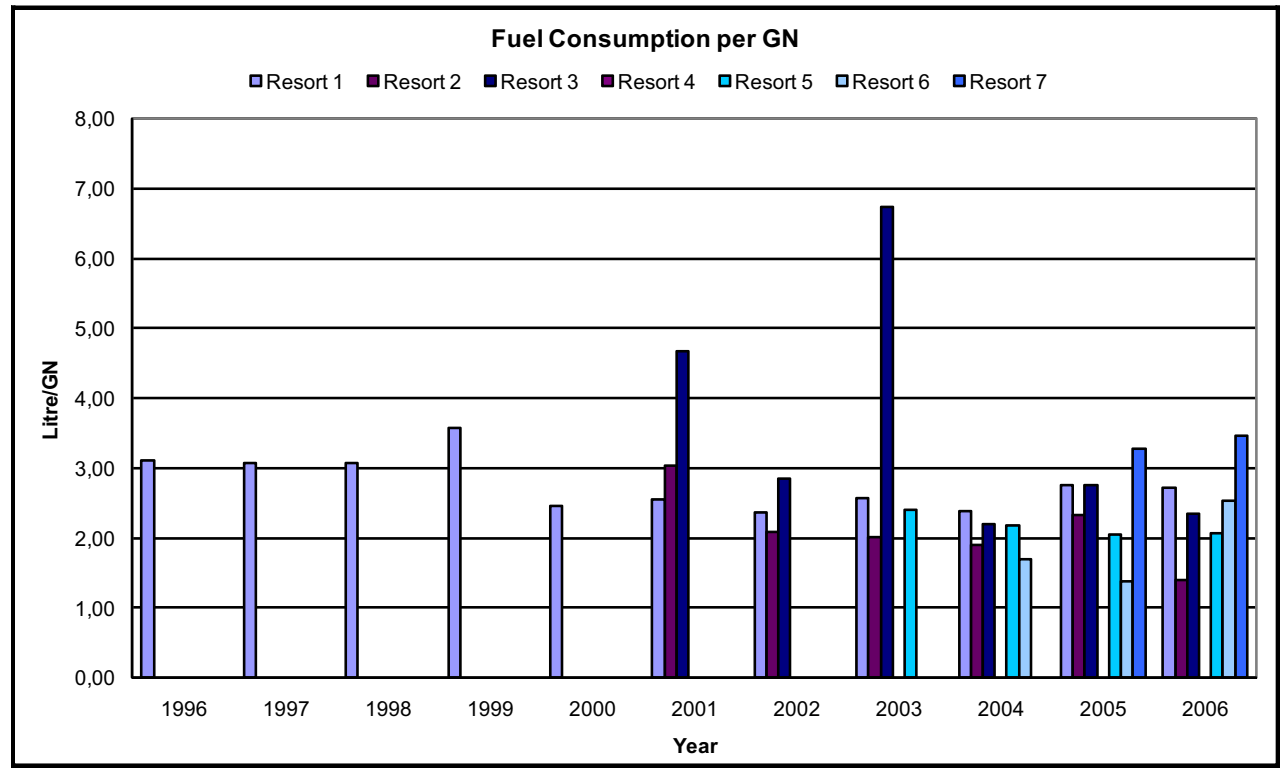

Figure 9: Average fuel consumption per GN in Sharm El-Sheikh.

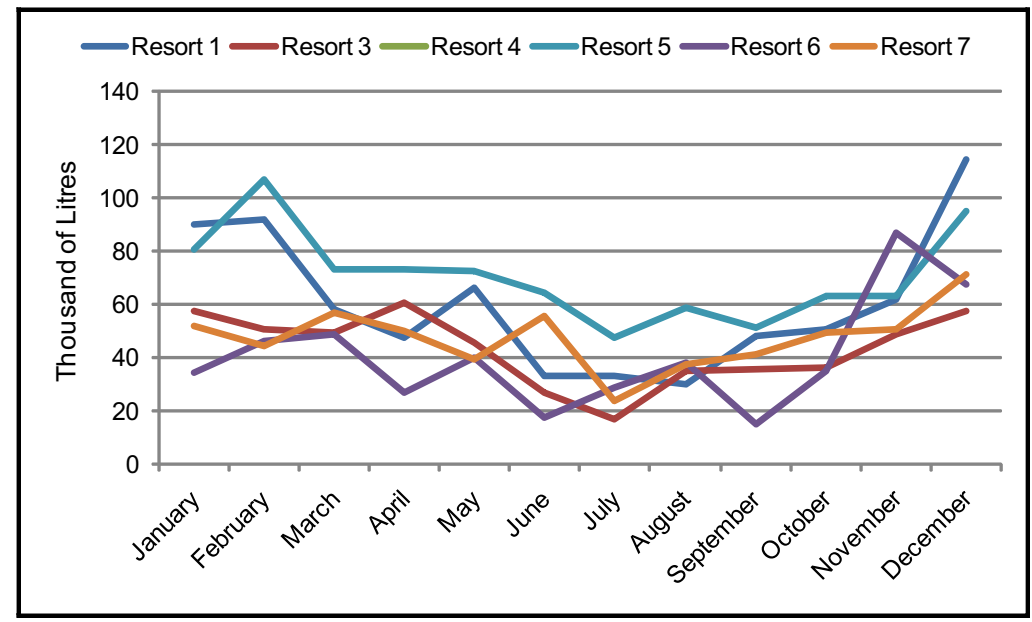

Figure 10: Monthly fuel consumption in 2006 at Sharm El-Sheikh resorts.

\subsubsection{Resorts water consumption}

Water consumption at any five star resort in Sharm El-Sheikh has a great impact on the total overall energy consumption through the following factors:

- Desalination plant's capacity and number of running hours;

- Wastewater treatment plant's capacity and number of running hours;

- Pumping system's capacity and running hours; 


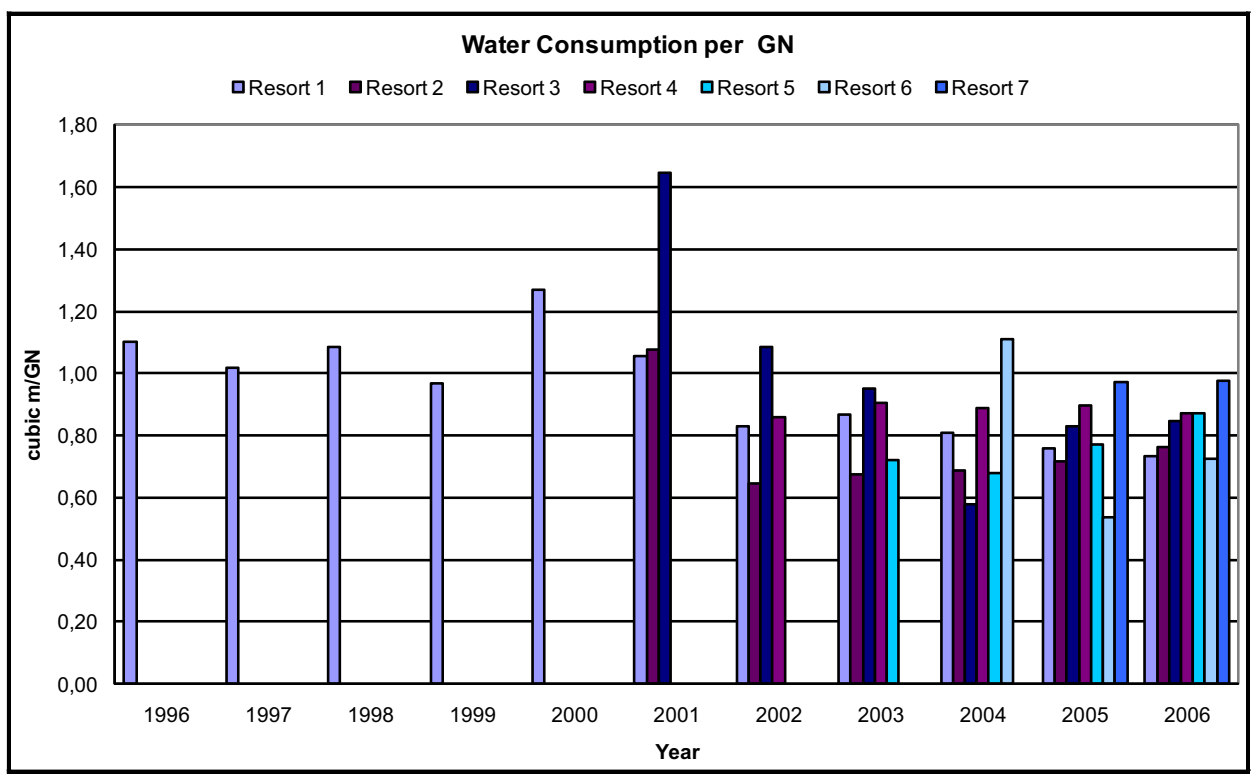

Figure 11: Average water consumption per GN at Sharm El-Sheikh resorts.

Table 4: Water consumption benchmarks for luxury hotels in $\mathrm{m}^{3} / \mathrm{GN}[16,17]$.

\begin{tabular}{lcccc}
\hline Evaluation & Excellent & Satisfactory & High & Excessive \\
\hline Temperate & $<0.50$ & $0.50-0.56$ & $0.56-0.90$ & $>0.90$ \\
Mediterranean & $<0.60$ & $0.60-0.75$ & $0.75-1.10$ & $>1.10$ \\
Tropical & $<0.90$ & $0.90-1.00$ & $1.00-1.40$ & $>1.40$ \\
\hline
\end{tabular}

- Energy required for supplying DHW;

- Size of swimming pools;

- Occupancy and number of guests;

- Number and size of facilities such as restaurants, outlets, health centers, etc.

Figure 11 shows that the water consumption per GN varies in the years 2002-2006 between 0.6 and $1 \mathrm{~m}^{3}$. Resort 1 had higher consumption rate in the earlier years which reduced down to ca. $0.80 \mathrm{~m}^{3}$ from 2001 onward. Those values compared with the benchmark for water consumptions in tropical and Mediterranean regions, defined by WWF (World Wide Fund for Nature) organization in the UK [16] as in Table 4, indicate a performance ranging from satisfactory to excellent based on tropical values while high to satisfactory based on Mediterranean values. Meanwhile, all resorts showed a steady consumption rate throughout the year.

\subsubsection{Occupancy versus consumption}

In order to get an overview of the total energy consumption, the different types of energy: electricity, fuel and LPG are converted to consumption costs by calculating the cost of each type of energy using the existing unit energy price. The occupancy data are analyzed against the consumption rates of 


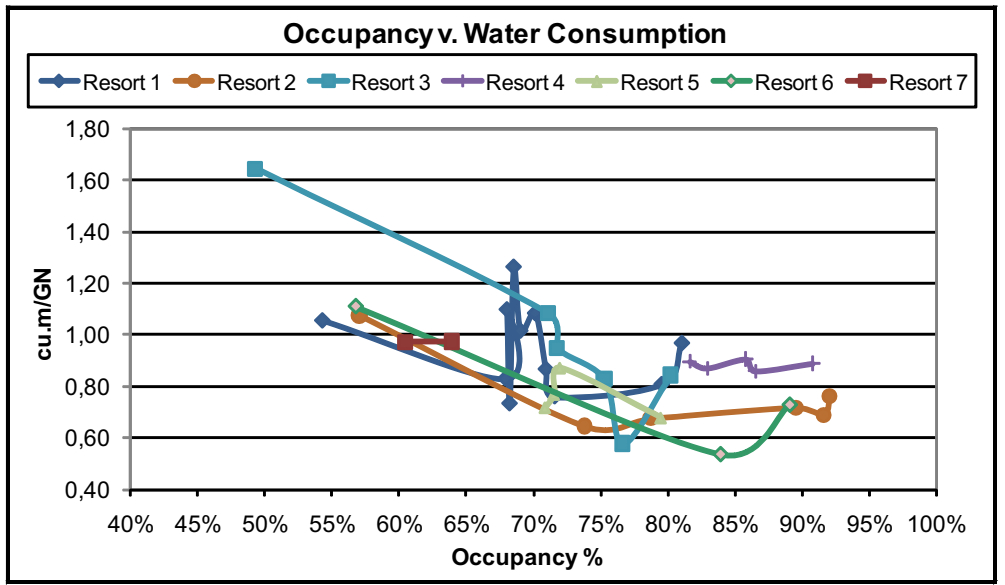

Figure 12: Occupancy vs. water consumption at Sharm El-Sheikh resorts.

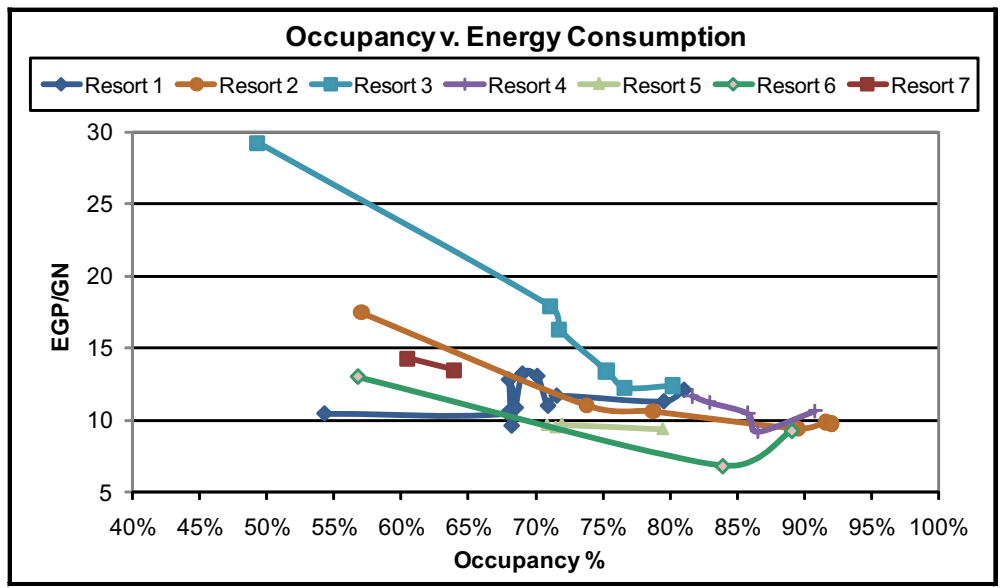

Figure 13: Occupancy vs. total energy consumption in Sharm El-Sheikh.

energy and water. Figure 12 shows that the water consumption pattern versus the occupancy rate while Figure 13 shows the total energy consumption expressed in EGP per GN. Although the consumption per GN decreases with the increase in occupancy, yet the relationship is not linear. However, it is noted that above an occupancy rate of $80 \%$, the consumption rate per GN does not vary greatly. The consumption intensity increases significantly when the occupancy rate falls below $70 \%$.

\subsection{Summary of the audit results}

The median value of the consumption rates for each resort is computed over the different years from 1996 to 2006 . Figure 14 provides an overview of the total energy consumption for the seven audited resorts in Sharm El-Sheikh. The consumption varies between 8.81 and 13.85 EGP/GN based on consumers energy prices of $0.22 \mathrm{EGP} / \mathrm{kWh}, 0.50 \mathrm{EGP} / \mathrm{l}$ and $1 \mathrm{EGP} / \mathrm{kg}$ for electricity, fuel and LPG, respectively at Sharm El-Sheikh in the year 2007/2008. 


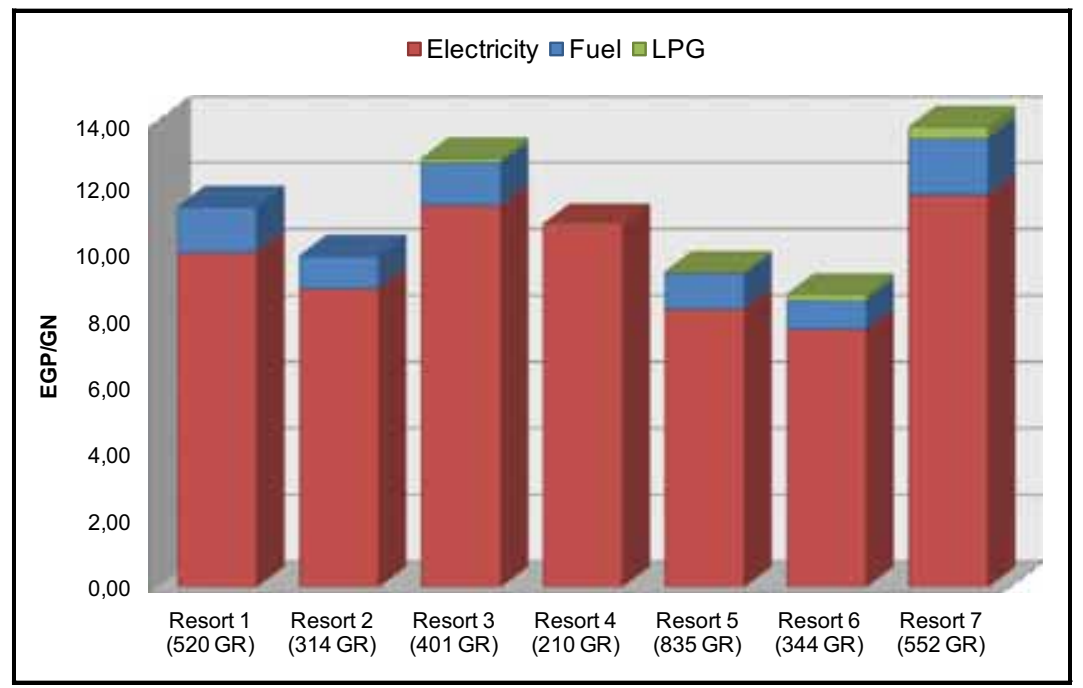

Figure 14: Summary of energy consumption for the audited resorts in Sharm El-Sheikh expressed in EGP per GN.

It is also to be noted that the energy performances of those resorts follow the same energy use patterns of other hotels worldwide as indicated earlier. However, considering the low power consumption of hotels in Majorca and Cyprus, there is potential to reduce the energy demand in Sharm El-Sheikh by switching to introducing energy efficiency measures and environmental management systems such as eco labels and environment standards (ISO 14001/EMAS) as well as switching to the use of solar energy.

The average equiv. $\mathrm{CO}_{2}$ emissions are calculated to be in the amount of $35 \mathrm{~kg}$ equiv. $\mathrm{CO}_{2}$ per $\mathrm{GN}$. For example, in the case of a resort with 340 guest rooms, the total annual $\mathrm{CO}_{2}$ emissions would amount to ca. 8,000 equiv. $\mathrm{CO}_{2}$ tonnes.

\section{CONCLUSION}

The results of the audit and analysis carried out on the seven resorts in Sharm El-Sheikh show that consumption rates are directly affected by occupancy level of a resort and that they tend to have the same pattern indicating the potential of establishing a benchmark for key performance indicators. The energy and water consumption of resorts in Sharm El-Sheikh are comparable with that of hotel in different parts of the world but also hold potential for reduction by introducing energy efficiency measures. This would lead to a reduction of minimum 2400 equiv. $\mathrm{CO}_{2}$ tonnes/year and resort. The survey also identifies the similarity in design concepts and lack of environmental practices adopted in Sharm El-Sheikh.

The investigation highlights the lack of published and recorded information about energy use in hotels in Egypt and the reluctance of hotels providing such information. The authors accordingly hope that the result of this research would be used as an initiator by the tourism and environmental authorities in Egypt to establish standards regarding energy consumptions in hotels and the establishment of a benchmark that can be used by designers, resort developers and hoteliers. The aim is to monitor and reduce energy consumption in new and renovated hotels and resorts. In addition, the government needs to provide incentives to investors and developers to encourage them to set environmental sustainability as a criterion in their design brief. 


\section{ACKNOWLDGEMENT}

The authors wish to acknowledge the cooperation of the 14 audited resorts by providing their energy and occupancy data.

\section{REFERENCES}

[1] UNWTO, Tourism Highlights, UNWTO Publications, 2010.

[2] Gössling, S., Global Environmental Consequences of Tourism. Global Environmental Change, 12, pp. 283-302, 2002. doi: http://dx.doi.org/10.1016/S0959-3780(02)00044-4

[3] Jurinčič, I. \& Bojnec, Š., Environmental management in Slovenian tourist enterprises. International Journal of Sustainable Development and Planning, 4(3), pp. 226-237, 2009. doi: http:// dx.doi.org/10.2495/SDP-V4-N3-226-237

[4] Kasim, A. \& Scarlat, C., Business environmental responsibility in the hospitality industry. Management, 2(1), pp. 5-23, 2007.

[5] MoT, Ministry of Tourism Program of Work, Cairo, 2006.

[6] USAID, EGYPT: Red Sea Sustainable Tourism, Cairo.

[7] Shaalan, I.M. 2005. Sustainable tourism development in the Red Sea of Egypt threats \& opportunities. Journal of Cleaner Production, 13: pp. 5. doi: http://dx.doi.org/10.1016/j. jclepro.2003.12.012

[8] Shackley, M. 1999. Tourism development and environmental protection in southern Sinai. Tourism Management, 20: pp. 6. doi: http://dx.doi.org/10.1016/S0261-5177(99)00022-9

[9] IEA,. World Energy Outlook 2005: Middle East and North Africa Insights. OECD/IEA, Paris, 2005.

[10] Environics, Prospects of the Renewable Energy Sector in Egypt: focus on photovoltaics and wind energy, Egyptian-German Private Sector Development Programme, Cairo, 2010.

[11] CD4CDM, Egypt CD4CDM - Final Report, Capacity Development for the Clean Development Mechanism (CD4CDM), Ministry of Trade \& Industry (MTI), Ministry of State for Environmental Affairs (MSEA), Cairo, 2006.

[12] Barakat, Y.F., Saad El-Din, A. \& Elewa, M.K., Clean Development Mechanism Benefits, Opportunities and Implementation in Egypt. Tebbin Institute for Metallurigcal Stidies (TIMS), Cairo, 2003.

[13] Egyptian State Information Service. Available from http://www.sis.gov.eg/En/Tourism/ Introduction., accessed in 2007.

[14] RSSTI, Best Practices for Energy Management, Tourism Development Authority (TDA), Egyptian Environment Policy Program (EEPP), US Agency for International Development (USAID), Giza, 2002.

[15] Bohdanowicz, P., and Martinac, I,. Detrimants and benchmarking of resource consumption in hotels-Case study of Hilton International and Scandic in Europe. Energy and Buildings: 13, 2007.

[16] Dodds, R., Why Environmental Benchmarking will help your hotel. The Prince of Wales International Buisnsess Leaders Forum's Tourism Partnership, UK, 2005.

[17] International Tourism Partnership, Scott Mycock und Claire Baker, Sustainable Hotel: Siting, Design and Construction. Conservation International (CI) and the Prince of Wales International Buisness Leaders Forum (ILBF), 2005a. 